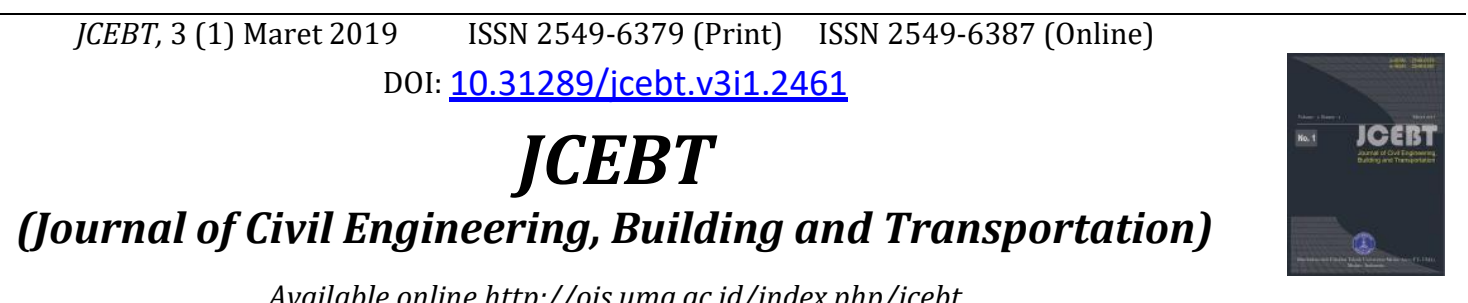

Available online http://ojs.uma.ac.id/index.php/jcebt

\title{
Analisa Runway Di Bandara Senubung Gayo Lues Aceh
}

\section{Analisys Runway at Airport Gayo Lues Aceh}

\author{
*Adam Malik ${ }^{1}$, Melloukey Ardan,2) \\ Program Studi Teknik Sipil, Fakultas Teknik \\ Universitas Medan Area, Indonesia \\ e-mail : malikarivamko81@gmail.com \\ Diterima: April 2019 ; Disetujui: Mei 2019 ; Dipublish: Mei 2019
}

\begin{abstract}
Abstrak
Bandar Udara adalah kawasan di daratan dan atau perairan dengan batas- batas tertentu yang digunakan sebagai tempat pesawat udara mendarat dan lepas landas, naik turun penumpang, bongkar muat barang.tujuannya adalah mengetahui kebutuhan Runway untuk penggunaan hingga 15 tahun yang akan datang, Analisis runway length sesuai dengan ketentuan ICAO Annex 14 dan Keputusan Menteri sebagai pembanding fasilitas alat bantu pendaratan. Dalam hal ini digunakan beberapa asumsi yang bersifat numeris dan argumentatif dalam perencanaan landas pacu Bandar Udara Senubung Gayo Lues Aceh untuk pesawat rencana jenis Boeing 737-200. Dan dari hasil penelitian dapat di simpulkan hasil perencanaan runway sepanjang 3366,29 m.
\end{abstract}

Kata Kunci : Bandar Udara Senubung Gayo Lues Aceh, runway , Boeing 737-200

\begin{abstract}
An airport is an area of land and or water with certain limits used as a place for aircraft landing and takeoff, up and down passenger, loading and unloading of goods, the airport is an important infrastructure in air transportation activities in each country, especially Indonesia which is a State islands where air transport plays an important role for the smooth activity of its inhabitants. The increasing need of the community in using the aircraft, the government will develop the dimension of the runway at Gayo Lues Airport. From the pioneering foundation to the national foundation, this is in because Gayon Lues Airport can be used in larger planes. The goal is to know Runway requirement for up to 15 years of use, Runway length analysis in accordance with ICAO Annex 14 provisions and Ministerial Decree as comparison of landing equipment facility. In this case, several numerical and argumentative assumptions are used in the planning of Gayo Lues Aceh Airport Amphitheater for the Boeing 737-200 plan aircraft. And from result of research can be concluded result of planning of runway along 3366,29 $\mathrm{m}$.

Key Words: Gayo Lues Aceh Amphitheater Airport, runway, Boeing 737-200
\end{abstract}

How to Cite: Malik, A, Nurmaidah, Dan Melloukey, A, (2019) Analisa Runway Di Bandara Senubung Gayo Lues Aceh. JCEBT (Journal of Civil Engineering, Building and Transportation). 3 (1): 11-18 


\section{PENDAHULUAN}

Transportasi adalah alat yang digunakan untuk mengangkut manusia, hewan dan barang ketempat tujuan, atau definisi yang lainnya yaitu memindahkan manusia, hewan dan barang dari tempat asalnya ketempat tujuannya dengan memakai suatu alat yang di gerakan oleh makhluk hidup atau mesin.Ada beberapa macam alat transportasi, yang pertama transportasi darat, transportasi udara dan transportasi laut. Fungsi dan peranan transportasi sangat penting dan strategis dalam kehidupan manusia yaitu sebagai pendorong, penggerak dan penunjang kegiatan pembangunan dalam segala sektor, baik sektor perhubungan, perdagangan, sosial dan ekonomi, maupun lingkungan. Bandar Udara merupakan prasarana penting dalam kegiatan transportasi udara pada setiap Negara khususnya Indonesia yang merupakan Negara kepulauan dimana transportasi udara sangat berperan penting bagi kelancaran aktivitas penduduknya. Perkembangan dunia penerbangan sangatlah besar perannya dalam melayani jasa transportasi udara.Hal ini diketahui dengan banyak berdirinya maskapaimaskapai penerbangan di dunia, yang bertujuan untuk memenuhi permintaan arus transportasi udara yang semakin luas jangkauannya dan padat arus lalulintasnya. Jasa transportasi udara membuat perjalanan sangat cepat dan efisien terutama untuk perjalanan yang sangat jauh. Bandar Udara Senubung Gayo Lues masih banyak tambahan dan perbaikan dibandingkan Bandara lainnya.

Dengan bertambahnya kebutuhan lalu lintas udara, maka di perlukan perencanaan runway agar terpenuhi permasalahan yang ada, yang disebabkan panjang runway yang ada tidak memenuhi pesawat yang berbadan besar.
Maksud penelitian ini adalah menganalisa perencanaan panjang runway di Bandara Senubung Gayo Lues. Tujuannya adalah memproleh kebutuhan panjang runway untuk penggunaan hingga 15 tahun yang akan datang.

Mengingat terbatasnya waktu serta terbatasnya kemampuan penulis dalam menghimpun data maka penulishanya member batasan pada:

1. Bandar Udara yang ditinjau adalah Bandar Udara Senubung Gayo Lues khususnya pada perencanaan runway yaitu pada perencanaan panjang runway tanpa memperhitungkan faktor ekonomi dan konstruksi perkerasan.

2. Perencanaan pengembangan panjang runway yang akan dibahas hanya pada tahap ini. Alat bantu pendaratan yang di bahas yaitu alat bantu pendaratan visual dan tidak membahas alat bantu navigasi.

3. Analisis runway length sesuai dengan ketentuan ICAO Annex 14 dan Keputusan Menteri sebagai pembanding fasilitas alat bantu pendaratan.

Penulisan skripsi ini diharapkan dapat memberikan manfaat bagi:

1. Peneliti

Penelitian ini dapat dipergunakan sebagai sarana untuk menambah pengetahuan, wawasan dan pengalaman, sebagai penerapan teori - teori yang di dapat di bangku kuliah dan dapat menjadi sebagai bekal ilmu khususnya teknologi pendidikan penerbangan kedepannya.

2. Perusahaan

Penelitian ini diharapkan dapat memberikan masukan kepada pengelola Bandara maupun pemerintah daerah mengenai kondisi fasilitas sisi udara. 


\section{Pengertian Bandar Udara}

Bandar Udara adalah kawasan di daratan dan atau perairan dengan batasbatas tertentu yang digunakan sebagai tempat pesawat udara mendarat dan lepas landas, naik turun penumpang, bongkar muat barang, dan tempat perpindahan antar moda transportasi, yang dilengkapi dengan fasilitas keselamatan dan keamanan penerbangan, serta fasilitas pokok dan fasilitas penunjang lainnya.

Suatu Bandar Udara mencakup suatu kumpulan kegiatan yang luas yang mempunyai kebutuhan-kebutuhan yang berbeda dan terkadang saling bertentangan antara satu kegiatan dengan kegiatan lainnya. Misalnya kegiatan keamanan membatasi sedikit mungkin hubungan ( pintu - pintu ) antara sisi darat (land side) dan sisi udara (air side) sedangkan kegiatan pelayanan memerlukan sebanyak mungkin pintu terbuka dari sisi darat kesisi udara agar pelayanan berjalan lancar. Kegiatan kegiatan itu saling tergantung satu sama lainnya sehingga suatu kegiatan tunggal dapat membatasi kapasitas dari keseluruhan kegiatan.

\section{Pengertian Landasan Pacu (Runway)}

Runway adalah jalur perkerasan yang di pergunakan oleh pesawat terbang untuk mendarat (landing) atau lepas landas (take off).

Menurut Horonjeff tahun 1988 system runway di suatu Bandara terdiri dari perkerasan struktur, bahu landasan(shoulder), bantal hembusan (blast pad)dan daerah aman runway(runway and safety area). Uraian dari system runway (dapat dilihat pada gambar 2.1)

\section{Lebar runway}

Dalam melakukan analisa lebar landaspacu (runway) baik untuk perencanaan pembangunan baru, maupun untuk perencanaan pengembangan landaspacu (runway) beberapa ketentuan klasifikasi lebar runway harus dipenuhi sebagai standar perencanaan Bandar Udara yaitu ketentuan ketentuan yang dikeluarkan oleh International Civil Organization (ICAO) Keadaan sekeliling Bandara juga mempengaruhi panjang pendeknya runway. Keadaan (Condition) yang penting diperhatikan adalah :

1. Temperatur

2. Surface wind

3. Runway Gradient ( Kemiringan Landasan )

4. Altitude of the airport ( ketinggian )

5. Condition of the runway surface

\section{Fasilitas Landasan Pacu}

Fasilitas landasan pacu juga mempunyai beberapa bagian yang masingmasingnya mempunyai persyaratan tersendiri, yaitu:

1. Runway shoulder (bahu landasan pacu)

2. Overrun mempunyai bagian meliputi clearway dan stopway

3. Turning area

4. Longitudinal slope

5. Transverse

6. Perkerasan landasan pacu

7. Kondisi permukaan landasan pacu

8. Kekuatan perkerasan landasan pacu

9. Runway strip

10. Holding bay

11. RESA (Runway End Safety Area)

\section{Faktor - Faktor Yang Mempengaruhi Panjang Runway}

\section{Lingkungan lapangan terbang}

Lingkungan lapangan terbang yang berpengaruh terhadap panjangn landasan : temperatur, angin permukaan, kemiringan landassan pacu, ketinggian dari permukaan laut, dan kondisi permukaan landasan. Seberapa jauh halhal di atas mempengaruhi landasan pacu, hanya merupakan pendekatan, namun demikian analisa terhadap ha-hal diatas 
akan menguntungkan terhadap perhitungan panjang landasan pacu.

Selanjutnya dalam perhitungan panjang landasan pacu, di pakai suatu standar yang di sebut "Aeroplane Reference Fielf Length" (ARFL) menurut ICAO, ARFL adalah landas pacu minimum yang di butuhkan untuklepas landa

Jadi didalam perencanaan persyaratan - persyaratan tersebut harus dipenuhi dengan melakukan koreksi akibat pengaruh dari keadaan lokal. Adapun uraian dari faktor koreksi tersebut adalah sebagai berikut:

\section{Koreksi ketinggian ( elevasi}

Menurut International civil aviation organization ( ICAO ) bahwa panjang runway bertambah sebesar $7 \%$ setiap kenaikan $300 \mathrm{~m}$ ( $1000 \mathrm{ft}$ ) dihitung dari ketinggian di atas permukaan laut.

Maka rumusnya adalah:

$\mathrm{Fe}=1+0,07 \frac{\mathrm{h}}{300}$

\section{Persamaan}

Dimana :

Fe : Faktor koreksi elevasi

$\mathrm{h}$ : Elevasi di atas permukaan laut (m)

Setelah panjang runway menurut ARFL diketahui di kontrol lagi dengan Aerodrome Reference Code (ARC) dengan tujuan untuk mempermudah membaca hubungan antara beberapa spesifikasi pesawat terbang dengan berbagai karakteristik Bandara.

\section{Perencanaan perkerasan struktural}

Perkerasan adalah struktur yang terdiri dari beberapa lapisan dengan kekerasan dan daya dukung yang berlainan, perkerasan yang di buat dari campuran aspal dengan agregat di gelar di atas suatu permukaan material granular mutu tinggi disebut perkerasan flexible, sedangkan perkerasan yang di buat dari slab-slab beton (portland cement concrete) disebut perkerasan "rigid" para ahli di indonesia belum sepakat apakah perkerasan beton dengan pondasi cakar ayam termasuk perkerasan flexible atau rigid. Dilihat dari betonnya memang rigid, tetapi dilihat dari filosophy- Cakar ayamnya termasuk flexible. Dalam $\mathrm{x}$ ini kita hanya membicarakan perkerasan rigid dan perkerasan flexible saja. Perkerasan berpungsi sebagai tumpuan rata-rata pesawat, permukaan yang rata menghasilkan jalan pesawat yang comport, dari pungsinya maka harus di jamin bahwa tiap-tiap lapisan dari atas ke bawah cukup kekerasan, dan ketebalannya sehingga tidak mengalami "Distress" (perubahan karna tidak mampu menahan bebab)

Perkerasan flexible terdiri dari lapisan surface corse, base coarse dan sabbase coarse, masing-masing bisa satu lapis bis lebih. Semuanya di gelar di atas tanah asli yang di padatkan di sebut sabgrade, lapisan subgrate bisa terletak di atas timbunan atau galian. Surface coarse terdiri dari campuran aspalt dan aggregate mempunyai rentang ketebalan dari $5 \mathrm{~cm}$, atau lebih.Fungsi utamanya adalah agar pesawat di kendarai di atas permukaan yang rata \& dan keselamaytan penerbangan, untuk menumpu beban roda pesawat dan menahan beban repetisi, serta membai beban tadi kepada lapisanlapisan di bawahnya. Base coarse bisa di buat dari material uang di persiapkan (di campur dengan semen atau aspal), bisa juga dari bahan-bahan alam tanpa campuran.seperti halnya surface coaarse lapisan ini harus mampu menahan beban, serta pengaruh-pengaruhnya dan membagi/meneruskan beban tadi kepada lapisan dibawahnya. Subbase coarse di 
buat dari material yang di perbaiki dulu, bisa juga material alam, sering lapisan ini di buat dengan menghamparkan pitrum (sirtu) apa adanya dari tempat pengambilan (Quarry) lalu di padatkan.

Perkerasan rigid terdiri dari slab-slab beton tebal $20 \mathrm{~cm}-6 \mathrm{~cm}$, di gelar diatas lapisan yang sudah di padat, lebih di sukai apabila lapisan di bawah beton di campur dengan semen atau aspal setebal $10 \mathrm{~cm}-$ $15 \mathrm{~cm}$, hal ini agar efek pompa (pumping) bisa di tekan sekecil mungkin.

\section{METODE PENELITIAN}

Materi pokok yang akan diteliti dalam skripsi ini adalah analisis pengembangan runway dan fasilitas alat bantu pendaratan apa saja yang ada di Bandar Udara Senubung Gayo Lues sesuai dengan yang disyaratkan dalam ICAO Annex 14 danKeputusan Menteri Perhubungan KM 47 tahun 2002.

\section{Tahap Penelitian}

Penelitian tersebut akan dilaksanakan dengan tahapan sebagai berikut:

\section{Tahap persiapan penelitian}

Persiapan penelitian meliputi penjabaran maksud dan tujuan penelitian, penyiapan metodelogi penelitian, check list kebutuhan pelaksanaan penelitian, kajian awal hasil studi kepustakaan dan perencanaan terkait.

\section{Tahap pengumpulan data}

1. Data primer

2. Data sekunder

\section{Tahap analisis}

Merupakan kajian data primer dan sekunder yang berupa analisis kebutuhan peningkatan kapasitas runway dan fasilitas alat bantu pendaratan guna antisipasi peningkatan kebutuhan angkutan udara.

\section{HASIL DAN PEMBAHASAN}

Direncanakan panjang landasan pacu yang dibutuhkan untuk lepas landas adalah $1990 \mathrm{~m}$, missal untuk menentukan panjang dan lebar landasan pacu dibutuhkan data-data sebagai berikut :

Maka panjang landasan pacu/ARFL adalah:

$$
\begin{aligned}
\mathrm{Fe} & =1+0,007 \times(\mathrm{h} / 300) \\
& =1+0,007 \times(850 / 300) \\
& =1,0198 \mathrm{~m} \\
\mathrm{Ft} & =1+0,01 \times(\mathrm{T}-0,0065 \mathrm{xh}) \\
& =1+0,01 \times(20-0,0065 \times 850) \\
& =1,1447 \\
\mathrm{FS} & =1+(0,1 \times \mathrm{s}) \\
& =1+(0,1 \times 2) \\
& =1,2
\end{aligned}
$$

Maka panjang Runway dibutuhkan (terkoreksi) $=$ ARFL $\times$ Fe $\times$ Ft $\times$ Fs $=1990 \times$ $1,0198 \times 1,1447 \times 1,2=2787,66 \mathrm{~m} .=$ $9143,55 \mathrm{ft}$

Jadi dari perhitungan di dapat panjang landasan sepanjang 2787,66m atau sama dengan $9143,55 \mathrm{ft}$,artinya lebih panjang di banding spesifikasi pabrik, yang hanya $1990 \mathrm{~m}$ atau sama dengan $6527,2 \mathrm{f}$

Operasi lepas landas:

Take-Off Distance $\quad=1,15 \quad \mathrm{x}$ panjang landasan pacu rencana

$$
\begin{aligned}
& =1,15 \times 2787,66 \mathrm{~m} \\
& =3205,80 \mathrm{~m}=10515,05 \mathrm{ft}
\end{aligned}
$$


Take-Off Run = panjang landasan pacu rencana $=2787,66 \mathrm{~m}=9143,52 \mathrm{ft}$

Lift-Off Distance $=0,55 \quad \mathrm{x}$ Take-Off Distance

$=0,55 \times 3205,80 \mathrm{~m}$

$=1763,19 \mathrm{~m}=5783,26 \mathrm{ft}$

a. Operasional pendaratan (Landing)

Landing distance (LD) $=$ TOD

$\mathrm{m}=10515,05 \mathrm{ft}$

Stop Distance (SD) $\quad=0,6 \times \mathrm{LD}$

$=0,6 \times 3205,80 \mathrm{~m}$

$=1923,48 \mathrm{~m}=6309,01 \mathrm{ft}$

Periksa!

$\mathrm{LD}=\mathrm{SD} / 0,6$

$=1923,48 / 0,6$

$=3205,80 \mathrm{~m} \ldots \ldots . .(\mathrm{ok})$

Clearway $(C W)=(0,5 \times$ (TOD-LOD $))$

$$
\begin{aligned}
& =(0,5 \times(3205,80-1763,19)) \\
& =721,30 \mathrm{~m}=2365,88 \mathrm{ft}
\end{aligned}
$$

Stopway $(\mathrm{SW})=0,05 \times \mathrm{LD}$

$$
\begin{aligned}
& =0,05 \times 3205,80 \mathrm{~m} \\
& =160,29 \mathrm{~m}=525,75 \mathrm{ft}
\end{aligned}
$$

Panjang total dari jalur landasan pacu dengan perkerasan penuh (full strength hardening) yang dibutuhkan adalah :

Field Length (FL) $\quad=$ Take-Off Run + $\left(0,5^{*}\right.$ (TOD-LOD) $)$

$=2787,66 \mathrm{~m}+(0,5 *(3205,80-1763,19))$

$=2787,66 \mathrm{~m}+721,305 \mathrm{~m}$

$=3508,96 \mathrm{~m}=11509,38 \mathrm{ft}$

b. Poor-approaches landing :
Landing Distance (LD) $=$ TOD

$=3205,80 \mathrm{~m}=10515,02 \mathrm{ft}$

Stop Distance (SD) $\quad=0,6 \times \mathrm{LD}$

$=0,6 \times 3205,80 \mathrm{~m}$

$=1923,48 \mathrm{~m}=6309,01 \mathrm{ft}$

Clearway $(\mathrm{CW})=0,15 \times \mathrm{LD}$

$=0,15 \times 3205,80 \mathrm{~m}$

$=1923,48 \mathrm{~m}=6309,01 \mathrm{ft}$

Stopway $(\mathrm{SW})=0,05 \times \mathrm{LD}$

$=0,05 \times 3205,80 \mathrm{~m}$

$=480,87 \mathrm{~m}=1577,25 \mathrm{ft}$

c. Overshoot take-off :

Landing Distance (LD)= TOD

$=3205,80 \mathrm{~m}=10515,02 \mathrm{ft}$

Lift-Off $\quad$ Distance $=0,75 \quad \mathrm{x} \quad$ Take-Off Distance

$=0,75 \times 3205,80$

$=2404,35 \mathrm{~m}=7886,26 \mathrm{ft}$

Clearway $(C W)=0,5 \times(T O D-L O D)$

$=0,5 \times(3205,80-2404,35)$

$=400,72 \mathrm{~m}=1314,37 \mathrm{ft}$

Stopway $(S W)=0,05 \times$ LD

$=0,05 \times 3205,80 \mathrm{~m}$

$=160,29 \mathrm{~m}=525,75 \mathrm{ft}$ 
d. Untuk Pesawat terbang lepas landas dengan kondisi kegagalan mesin, sehingga harus melakukan emergency landing :

Landing Distance (LD) $=$ TOD

$=3205,80 \mathrm{~m}=10515,02 \mathrm{ft}$

Stop Distance (SD) $=0,6 \times \mathrm{LD}$

$=0,6 \times 3205,80 \mathrm{~m}$

$=1923,48 \mathrm{~m}=6309,01 \mathrm{ft}$

Clearway $(C W)=0,15 \times$ LD

$$
\begin{aligned}
& =0,15 \times 3205,80 \mathrm{~m} \\
& =480,87 \mathrm{~m}=1577,25 \mathrm{ft}
\end{aligned}
$$

Stopway $(\mathrm{SW})=0,05 \times \mathrm{LD}$

$$
\begin{aligned}
& =0,05 \times 3205,80 \mathrm{~m} \\
& =160,29 \mathrm{~m}=5257,512 \mathrm{ft}
\end{aligned}
$$

e. Untuk kondisi kegagalan mesin pada pesawat terbang, panjang jalur landasan pacu yang dibutuhkan adalah

Field Length (FL) $=$ Take-Off Run + Stopway

$$
\begin{aligned}
& =3205,80 \mathrm{~m}+160,29 \mathrm{~m} \\
& =3366,29 \mathrm{~m}=11040,77 \mathrm{ft}
\end{aligned}
$$

Maka accelerate-stop distance $=$ Field Length

$$
=3366,29 \mathrm{~m}=11040,77 \mathrm{ft}
$$

Jadi dari hasil perhitungan kita mendapat panjang landasan Normal $3205,80 \mathrm{~m}$ atau sama dengan $=10515,02 \mathrm{ft}$, dan lebih panjang di bandingkan dengan spesifikasi pabrik, yang dengan panjang
$1990 m$ atau sama dengan 6527,2. Yang selisihnya adalah 3205,80 di kurang 1990 adalah $1215,8 \mathrm{~m}$ atau sama dengan $3987,82 \mathrm{ft}$

\section{SIMPULAN}

Perencanaan landas pacu sebuah bandar udara adalah salah satu perencanaan yang sangat unik karena belum tentu dapat diprediksi berdasarkan angka-angka yang ada, banyak faktor pendukung lain yang mempengaruhi perencanaan landasan pacu sebuah bandar udara. Dalam hal ini digunakan asumsi yang bersifat argumentatif dalam perencanaan landas pacu Bandar Udara Senubung Gayo Lues Aceh untuk pesawat rencana jenis Boeing 737-200.Dari hasil penelitian dapat di simpulkan hasil perencanaan runway sepanjang 3205,80m,

Untuk umur rencana analisa ini direncanakan sampai dengan tahun 2030 (15 th ) ini dilihat dari perhitungan lalulintas pesawat yang ada dengan acuan pesawat terbesar pesawat Boeing 737200.

Perlu diperhatikan kembali aspek fasilitas teknik sisi udara seperti perencanaan runway yang harus memenuhi persyaratan standarisasi menurut ICAO, taxiway ( penghubung landasan pacu), posisi apron ( tempat parker pesawat ), Drainase yang sudah memenuhi Persyaratan.

\section{DAFTAR PUSTAKA}

Basuki heru, ir " merancang dan merencanakan lapangan terbang" bandung 1986

Jurnal sipil statik vol.1 no.4, maret 2013 (270-275) issn "studi pengembangan sisi udara bandar udara mali kabupaten alor untuk jenis pesawat boeing 737-200 
Malik, A, Nurmaidah, Dan Melloukey, A, (2019) Analisa Runway Di Bandara Senubung Gayo Lues Aceh.

Jurnal sipil statik vol.1 no.4, maret 2013 (270-275) issn:2337-6732

Peraturan menteri perhubungan nomor : $\mathrm{km} 24$ tahun 2009, tentang "peraturan keselamatan penerbangan sipil "

"Peraturan direktorat jenderal perhubungan udara" nomor : skep/77/vi/2005, tentang persyaratan teknis pengoperasian fasilitas teknik bandar udara

Samapaty, a. u. r., et.al., "studi pengembangan sisi udara bandar udara mali kabupaten alor untuk jenis pesawat boeing 737-200 